\title{
Identification of putative phenotype-modifying genetic factors associated with phenotypic diversity in Brooke-Spiegler syndrome
}

Nikoletta Nagy ( $\nabla$ nikoletta.nagy@gmail.com )

Szegedi Tudomanyegyetem https://orcid.org/0000-0001-8576-7953

Éva Melinda Pap

Szegedi Tudomanyegyetem Szent-Gyorgyi Albert Klinikai Kozpont

Katalin Farkas

Szegedi Tudomanyegyetem Szent-Gyorgyi Albert Klinikai Kozpont

Márta Széll

Szegedi Tudomanyegyetem Szent-Gyorgyi Albert Klinikai Kozpont

\section{Gábor Németh}

Szegedi Tudomanyegyetem Szent-Gyorgyi Albert Klinikai Kozpont

Neil Rajan

Newcastle University Institute of Genetic Medicine

\section{Research article}

Keywords: Brooke-Spiegler syndrome, phenotype-modifying genetic factors, STAT3 gene, TRAF3 gene, NBR1 gene

Posted Date: December 19th, 2019

DOI: https://doi.org/10.21203/rs.2.19321/v1

License: (9) This work is licensed under a Creative Commons Attribution 4.0 International License. Read Full License 


\section{Abstract}

Background: Brooke-Spiegler syndrome (BSS; OMIM 605041) is a rare monogenic skin disease characterized by the development of skin appendage tumors caused by mutations in the cylindromatosis (CYLD) gene. Despite the described phenotypes and reports of the underlying CYLD mutations, it has been difficult to establish genotype-phenotype correlations in BSS. We recently investigated two BSS pedigrees (Hungarian with Bukovinian origin and Anglo-Saxon), in which the affected family members exhibit striking differences in their phenotypes - despite carrying the same disease-causing mutation (c.2806C >T, p.Arg936Ter) of the CYLD gene. The aim of our study was to identify phenotype-modifying genetic factors to further the understanding of genotype-phenotype correlations in BSS.

Results: In a comparison of whole exome sequencing data from the Hungarian and Anglo-Saxon BSS patients, we have identified three putative phenotype-modifying genetic variants: the rs 1053023 SNP of the signal transducer and activator of transcription 3 (STAT3) gene, the rs1131877 SNP of the tumor necrosis factor receptor-associated factor 3 (TRAF3) gene and the rs202122812 SNP of the neighbor of BRCA1 gene 1 (NBR1) gene.

Conclusions: Our study contributes to the accumulating evidence for the clinical importance of phenotype-modifying genetic factors, which are potentially important for the elucidation of genotypephenotype correlations and disease prognosis.

\section{Background}

Brooke-Spiegler syndrome (BSS; OMIM 605041 syn. CYLD cutaneous syndrome) is a rare monogenic skin disease characterized by the development of skin appendage tumors, such as cylindromas, trichoepitheliomas and spiradenomas [1,2]. The gene responsible for the development of BSS is the cylindromatosis (CYLD) gene localized on 16q12-q13 [2]. To date, a more than 95 different diseasescausing mutations have been published for the CYLD gene [3]. It is difficult to establish genotypephenotype correlations for BSS, despite reports of the phenotypes and the associated CYLD mutations. Clearly, genotype-phenotype correlations might have significant clinical relevance with respect to understanding the disease mechanism(s), prognosticating clinical outcome for patients, as well as to the development of future therapeutic modalities. A significant challenge that exists is that patients with identical mutations of the CYLD gene can present with different phenotypic features, ranging from BSS to familial cylindromatosis (FC; OMIM 132700) and multiple familial trichoepithelioma type 1 (MFT1; OMIM 601606), suggesting additional genetic factors impact on the presentation of clinical variants of the CYLD mutation-caused spectrum $[4,5]$.

Here we report an investigation of Bukovinian and Anglo-Saxon BSS pedigrees, which have been chosen as they both carry a recurrent germline mutation in the CYLD gene (c.2806C > T, p.Arg936Ter), yet show striking difference in their phenotypes: the Bukovinian family exhibits numerous types of severe phenotypes and extremely enlarged skin appendage tumors, whereas the Anglo-Saxon pedigree exhibits a 
significantly milder phenotype [6]. These two pedigrees provide an excellent opportunity to identify phenotype-modifying genetic factors that potentially facilitate the understanding of genotype-phenotype correlations in BSS. In this study, we employed whole exome sequencing (WES) to comprehensively profile coding variants and identify putative phenotype-modifying genetic factors, which could potentially explain the observed clinical differences between the Bukovinian and the Anglo-Saxon BSS pedigrees carrying the same causative CYLD mutation.

\section{Materials And Methods}

\section{Patients}

A Hungarian pedigree from Bukovina (Romania) affected by BSS and an English BSS pedigree from Northern England were included in this study. The clinical phenotypes of the affected family members and the pedigrees are reported in detail in a previous paper from our research group [6].

\section{Whole exome sequencing (WES)}

Previously we have reported that the two enrolled BSS families (Hungarian from Bukovina, Romania, and Anglo-Saxon from the vicinity of Newcastle, England) are carrying the same disease-causing mutation (c.2806C >T, p.Arg936Ter) of the CYLD gene [6]. WES was performed by UD-GenoMed Medical Genomic Technologies Ltd. (Debrecen, Hungary, http://www.ud-genomed.hu/) with DNA samples from two affected individuals of both families. The quality of the DNA samples was evaluated by agarose-gel electrophoresis analysis. Four micrograms of DNA with a concentration $100 \mathrm{ng} / \mu$ l were used for library construction. The Agilent liquid chip capture system was used to efficiently enrich all human exon regions. High-throughput deep sequencing was subsequently performed on the Illumina platform. The Agilent SureSelect Human All Exon V6 Kit was used for library construction and the capture experiments. The Agilent 2100 system was subsequently used to verify the library insert size. The Illumina platform was used for sequencing according to the effective concentration of the library and the data output requirements. High-throughput paired-end sequencing was performed (paired-end 150 bp, PE150). After WES was completed, bioinformatics analysis was performed, including sequencing data quality assessment, single-nucleotide polymorphism (SNP) detection and whole-genome association analysis. The sequencing data quality-control requirements were as follows: the sequencing error rate of each base position was less than $1 \%$, the average Q20 ratio was higher than $90 \%$, the average Q30 ratio was greater than $80 \%$, the average error rate was less than $0.1 \%$, the sequencing reads achieved an alignment rate of $95 \%$ or greater, and the read depth of the base at one position reached 10X or more. SNP testing was performed as follows: high-quality sequences were aligned with the human reference genome (GRCh37/hg19) to detect sequence variants in the sample, and the detected variations were analyzed and annotated. Sanger sequencing validation in this study was performed by Delta Bio $2000 \mathrm{Ltd}$. (Szeged, Hungary, http://www.deltabio.hu/).

\section{Results}


The comparison of the WES data from the two Bukovinian and the two Anglo-Saxon family members identified three putative phenotype-modifying polymorphisms, all of which are common SNPs and present only in the Bukovinian individuals: the rs 1053023 SNP of the signal transducer and activator of transcription 3 (STAT3) gene, the rs 1131877 SNP of the tumor necrosis factor receptor-associated factor 3 (TRAF3) gene and the rs202122812 SNP of the neighbor of BRCA1 gene 1 (NBR1) gene. The rs1053023 polymorphism is located in the 3'UTR region of the STAT3 gene, while the other two polymorphisms (rs1131877 and rs202122812) are common missense variants of the TRAF3 and NBR1 genes, respectively. Pathogenicity predictions of the identified phenotype-modifying factors are summarized in Table 1.

Table 1

Pathogenicity predictions and clinical associations of the identified phenotype-modifying factors.

\begin{tabular}{|c|c|c|c|c|}
\hline $\begin{array}{l}\text { SNP } \\
\text { (gene) }\end{array}$ & $\begin{array}{l}\text { Location (variant } \\
\text { type) }\end{array}$ & $\begin{array}{l}\text { SIFT } \\
\text { Polyphen2 } \\
\text { MutationTaster } \\
\text { (analysis) }\end{array}$ & Clinical associations & References \\
\hline $\begin{array}{l}\text { rs1053023 } \\
\text { (STAT3) }\end{array}$ & 3' UTR variant & $\begin{array}{l}- \\
\text { Polymorphism }\end{array}$ & $\begin{array}{l}\text { Multiple sclerosis } \\
\text { B-NHL } \\
\text { BSS }\end{array}$ & $\begin{array}{l}17 \\
18 \\
\text { This study }\end{array}$ \\
\hline $\begin{array}{l}\text { rs1131877 } \\
\text { (TRAF3) }\end{array}$ & Exonic (missense) & $\begin{array}{l}\text { Tolerated } \\
\text { Benign } \\
\text { Polymorphism }\end{array}$ & $\begin{array}{l}\text { Postradiotherapy } \\
\text { toxicity } \\
\text { BSS }\end{array}$ & $\begin{array}{l}25 \\
\text { This study }\end{array}$ \\
\hline $\begin{array}{l}\text { rs202122812 } \\
\text { (NBR1) }\end{array}$ & $\begin{array}{l}\text { Exonic } \\
\text { (missense) }\end{array}$ & $\begin{array}{l}\text { Deleterious } \\
\text { Probably damaging } \\
\text { Disease causing }\end{array}$ & BSS & This study \\
\hline
\end{tabular}

\section{Discussion}

Although the identification of disease-causing mutations is still extremely important for therapy and family planning, direct sequencing is unable to answer clinically relevant questions regarding genotypephenotype correlations and disease prognosis [7]. This limitation of direct sequencing was encountered with the Bukovinian and Anglo-Saxon BSS pedigrees reported previously by our workgroup [6]. Despite the fact that the same disease-causing CYLD mutation was identified in the affected members of both families, the causative mutation itself does not explain the striking phenotypic differences observed between the two families and is unable to facilitate disease prognosis.

Comparing the WES data of the Bukovinian and Anglo-Saxon BSS patients, we identified three putative phenotype-modifying genetic variants that potentially explain the striking phenotypic differences among patients carrying the same disease-causing CYLD mutation. STAT3 is a transcription factor, which is constitutively activated in a variety of human cancers and plays critical roles in cancer cell survival, metastasis and angiogenesis [8, 9]. STAT3 is activated by interleukin-6 (IL-6) and directly activates 
microRNAs (miRs), such as miR-21 and miR-181b-1 [10]. MiR-21 and miR-181b-1 inhibit the enzymatic activity of CYLD, leading to increased nuclear factor-KB (NF-KB) activity. Thus, STAT3 is not only a downstream target of IL-6 but, with miR-21, miR-181b-1 and CYLD, is part of the positive feedback loop that underlies the epigenetic switch that links inflammation to cancer $[10,11]$. The B-cell CLL/lymphoma 3 (BCL3) protein, which directly interacts with the STAT3 protein, is deubiquitinated by the CYLD enzyme, and abnormal BCL3 ubiquitination has been associated with the development of basal cell carcinomas (BCCs) [12]. It has been recently reported that BCL3 serves as an oncogene in cervical cancer and its oncogenic effect is mediated by STAT3 [13]. Interestingly, the rs1053023 SNP of the STAT3 gene has already been associated with multiple sclerosis and reported in B-cell non-Hodgkin lymphoma (B-NHL) [14]. However, this is the first study that suggests a potential phenotype-modifying role for STAT3 in BSS (Fig. 1).

TRAF3 is a member of the TRAF family of proteins, which serve as both crucial intracellular adaptors and E3 ubiquitin ligases that mediate signaling after the activation of various receptors. Receptors that signal through TRAF proteins include those involved in inflammation, innate immune responses, and cell death and, most notably, interact with the following: tumor necrosis factor receptors (TNFR), Toll-like receptors (TLRs), RIG-1-like receptors (RLRs) and interleukin-1 receptors (IL-1Rs) $[15,16]$. The TRAF-interacting protein (TRAIP) interacts with TRAF3, while TRAIP is reported to interact with CYLD [17]. TRAIP expression is increased in BCCs and in multiple breast epithelial cell lines with oncogenic potentials ranging from non-malignant to highly invasive $[18,19]$. Mutations in TRAF3 and CYLD leading to constitutive activation of NF-KB have been identified in cancers, including multiple myeloma and solid tumors [20]. The rs1131877 SNP of the TRAF3 gene is highly predictive for the development grade $\geq 2$ acute esophageal postradiotherapy toxicity [21], and here we have demonstrated its association with the phenotypic diversity in BSS (Fig. 1).

NBR1 is an autophagic adaptor protein involved in the efficient clearance of damaged mitochondria. Briefly, upon mitochondrial damage, E3 ubiquitin ligases are recruited from the cytosol to depolarized mitochondria, where they target damaged mitochondrial proteins for ubiquitination and bulk degradation by autophagy $[22,23]$. NBR1 is a functional homolog of sequestosome 1 (SQSTM1), another autophagic adaptor protein, which is a selective autophagy substrate that also act as cargo receptors for degradation of other substrates [24]. The interaction of CYLD with TRAFs is dependent upon SQSTM1, and the absence of SQSTM1 results in the reduction of the activity of the CYLD enzyme [25, 26]. The rs202122812 SNP of the NBR1 gene has not been previously associated with any human diseases: this is the first study to indicate its clinical relevance in the development of the BSS-related phenotypic diversity (Fig. 1).

Within monogenic diseases, cystic fibrosis (CF) provides a good example for the clinical relevance of the phenotype-modifying genetic factors, as genetic modifiers identified for this disease have been shown to contribute to variable disease phenotype. In particular, it has been recently reported that the mutations in the hemochromatosis (HFE) gene are associated with disease severity in adults with CF [27]. Genetic 
modifiers have also been reported for ichthyosis, a monogenic skin disease, and these modifiers were found to be associated with increased IgE levels and allergic sensitizations [28].

\section{Conclusions}

With the identification of phenotype-modifying genetic polymorphisms, our study aimed to explain phenotypic diversity in BSS. In addition to these phenotypic modifying genetic variants, environmental or lifestyle factors might also contribute to the phenotypic diversity of BSS. Concerning the identified genetic phenotype modifiers, further functional studies are needed to prove their clinical relevance and verify the underlying mechanism of their phenotype-modifying roles. It would be of interest to explore our findings in further BSS pedigrees to determine the role of the SNPs identified and to investigate additional phenotypic modifiers. Our study contributes to the accumulating evidence describing the clinical importance of phenotype-modifying genetic factors, which have high potential in the elucidation of genotype-phenotype correlations or disease prognosis [29].

\section{Declarations}

\section{Ethics approval and consent to participate}

The investigation was approved by the Internal Review Board of the University of Szeged. Written informed consent was obtained from the patients and unrelated healthy individuals. The study was conducted according to the Principles of the Declaration of Helsinki.

\section{Consent for publication}

All the reported patients gave their informed consent to the publication.

\section{Availability of data and material}

All available data are included within the article.

\section{Competing interests}

The authors declare that they have no competing interests.

\section{Funding}

This research was supported by GINOP-2.3.2-15-2016-00039 grant and EFOP-3.6.1-16-2016-00008 grant. Neil Rajan was funded by a Wellcome Trust Fellowship WT097163MA.

\section{Authors' contributions}

ÉMP contributed to analysis, interpretation, and drafted the manuscript. KF contributed to design, analysis and interpretation, and critically revised the manuscript. MS and GN contributed to conception, 
design, interpretation, and critically revised the manuscript. NR and NN were mentors who guided the research study, contributed to conception, design, interpretation, and drafted and critically revised the manuscript. All authors read and approved the final manuscript.

\section{Acknowledgements}

We would like to thank all the patients for their contribution to the extended examinations.

\section{Abbreviations}

BSS: Brooke-Spiegler syndrome

CYLD: cylindromatosis gene

STAT3: signal transducer and activator of transcription 3

TRAF3: tumor necrosis factor receptor-associated factor 3

NBR1: neighbor of BRCA1 gene 1

WES: whole exome sequencing

IL-6: interleukin-6

NF-KB: nuclear factor kappa-light-chain-enhancer of activated B cells

BCL3: B-cell lymphoma 3

BCCs: basal cell carcinomas

B-NHL: B-cell non-Hodgkin lymphoma

TNFR: tumor necrosis factor receptors

TLRs: Toll-like receptors

RLRs: RIG-1-like receptors

IL-1Rs: interleukin-1 receptors

TRAIP: TRAF-interacting protein

SQSTM1: sequestosome 1

CF: cystic fibrosis

HFE: hemochromatosis gene 


\section{References}

1. Evans CD. Turban tumour. Br J Dermatol. 1954;66:434-43.

2. Bignell GR, Warren W, Seal S, Takahashi M, Rapley E, Barfoot R, et al. Identification of the familial cylindromatosis tumour suppressor gene. Nat Genet. 2000;25:160-5.

3. Nagy N, Farkas K, Keméyn L, Széll M. Phenotype-genotype correlations for clinical variants caused by CYLD mutations. Eur J Med Genet. 2015;58:271-8.

4. Rajan N, Burn J, Langtry J, Sieber-Blum M, Lord CJ, Ashworth A. Transition from cylindroma to spiradenoma in CYLD-defective tumours is associated with reduced DKK2 expression. J Pathol. 2011;224:309-21.

5. Rajan N, Elliott R, Clewes O, Mackay A, Reis-Filho JS, Burn J, et al. Dysregulated TRK signaling is a therapeutic target in CYLD defective tumors. Oncogene. 2011;30:4243-60.

6. Nagy N, Rajan N, Farkas K, Kinyó A, Kemény L, Széll M. A Mutational Hotspot in CYLD Causing Cylindromas: A Comparison of Phenotypes Arising in Different Genetic Backgrounds. Acta Derm Venereol. 2013;93:743-5.

7. Jarinova O, Ekker M. Regulatory variations in the era of next-generation sequencing: implications for clinical molecular diagnostics. Hum Mutat. 2012;33:1021-30.

8. Yu H, Pardoll D, Jove R. STATs in cancer inflammation and immunity: a leading role for STAT3. Nat Rev Cancer. 2009;9:798-809.

9. Aggarwal BB, Kunnumakkara AB, Harikumar KB, Gupta SR, Tharakan ST, Koca C, et al. Signal transducer and activator of transcription-3, inflammation, and cancer: how intimate is the relationship? Ann N Y Acad Sci. 2009;1171:59-76.

10. Iliopoulos D, Jaeger SA, Hirsch HA, Bulyk ML, Struhl K. STAT3 activation of miR-21 and miR-181b-1 via PTEN and CYLD are part of the epigenetic switch linking inflammation to cancer. Mol Cell. 2010;39:493-506.

11. Xu DD, Zhou PJ, Wang Y, Zhang L, Fu WY, Ruan BB, et al. Reciprocal activation between STAT3 and miR-181b regulates the proliferation of esophageal cancer stem-like cells via the CYLD pathway. Mol Cancer. 2016;15:40.

12. Chaudhary SC, Tang X, Arumugam A, Li C, Srivastava RK, Weng Z, et al. Shh and p50/Bcl3 signaling crosstalk drives pathogenesis of BCCs in Gorlin syndrome. Oncotarget. 2015;6:36789-814.

13. Zhao H, Wang W, Zhao Q, Hu G, Deng K, Liu Y. BCL3 exerts an oncogenic function by regulating STAT3 in human cervical cancer. Onco Targets Ther. 2016;9:6619-29.

14. Butterbach K, Beckmann L, de Sanjosé S, Benavente Y, Becker N, Foretova L, et al. Association of JAK-STAT pathway related genes with lymphoma risk: results of a European case-control study (EpiLymph). Br J Haematol. 2011;153:318-33.

15. Wang Y, Zhang P, Liu Y, Cheng G. TRAF-mediated regulation of immune and inflammatory responses. Sci China Life Sci. 2010;53:159-68. 
16. Hacker $\mathrm{H}$, Tseng $\mathrm{PH}$, Karin M. Expanding TRAF function: TRAF3 as a tri-faced immune regulator. Nat Rev Immunol. 2011;11:457-68.

17. Chapard C, Hohl D, Huber M. The role of the TRAF-interacting protein in proliferation and differentiation. Exp Dermatol. 2012;21:321-6.

18. Almeida S, Ryser S, Obarzanek-Fojt M, Hohl D, Huber M. The TRAF-interacting protein (TRIP) is a regulator of keratinocyte proliferation. J Invest Dermatol. 2011;131:349-57.

19. Zhou Q, Geahlen RL. The protein-tyrosine kinase Syk interacts with TRAF-interacting protein TRIP in breast epithelial cells. Oncogene. 2009;28:1348-56.

20. Harhaj EW, Dixit VM. Regulation of NF-kappaB by deubiquitinases. Immunol Rev. 2012;246:107-24.

21. De Ruyck K, Sabbe N, Oberije C, Vandecasteele K, Thas O, De Ruysscher D, et al. Development of a multicomponent prediction model for acute esophagitis in lung cancer patients receiving chemoradiotherapy. Int J Radiat Oncol Biol Phys. 2011;81:537-44.

22. Shi J, Fung G, Deng H, Zhang J, Fiesel FC, Springer W, et al. NBR1 is dispensable for PARK2-mediated mitophagy regardless of the presence or absence of SQSTM1. Cell Death Dis. 2015;6:e1943.

23. Shi J, Fung G, Piesik P, Zhang J, Luo H. Dominant-negative function of the C-terminal fragments of NBR1 and SQSTM1 generated during enteroviral infection. Cell Death Differ. 2014;21:1432-41.

24. Svenning S, Lamark T, Krause K, Johansen T. Plant NBR1 is a selective autophagy substrate and a functional hybrid of the mammalian autophagic adapters NBR1 and p62/SQSTM1. Autophagy. 2011;7:993-1010.

25. Wooten MW, Geetha T, Babu JR, Seibenhener ML, Peng J, Cox N, et al. Essential role of sequestosome 1/p62 in regulating accumulation of Lys63-ubiquitinated proteins. J Biol Chem. 2008;283:6783-9.

26. Into T, Inomata M, Niida S, Murakami Y, Shibata K. Regulation of MyD88 aggregation and the MyD88-dependent signaling pathway by sequestosome 1 and histone deacetylase 6. J Biol Chem. 2010;285:35759-69.

27. Smith DJ, Klein K, Hartel G, Wainwright CE, Bell SC, Anderson GJ, Reid DW. Mutations in the HFE gene can be associated with increased lung disease severity in cystic fibrosis. Gene. 2019;683:12-7.

28. Kiritsi D, Valari M, Fortugno P, Hausser I, Lykopoulou L, Zambruno G, et al. Whole-exome sequencing in patients with ichthyosis reveals modifiers associated with increased IgE levels and allergic sensitizations. J Allergy Clin Immunol. 2015;135:280-3.

29. Lee DS, Park J, Kay KA, Christakis NA, Oltvai ZN, Barabási AL. The implications of human metabolic network topology for disease comorbidity. Proc Natl Acad Sci U S A. 2008;105:9880-5.

\section{Figures}



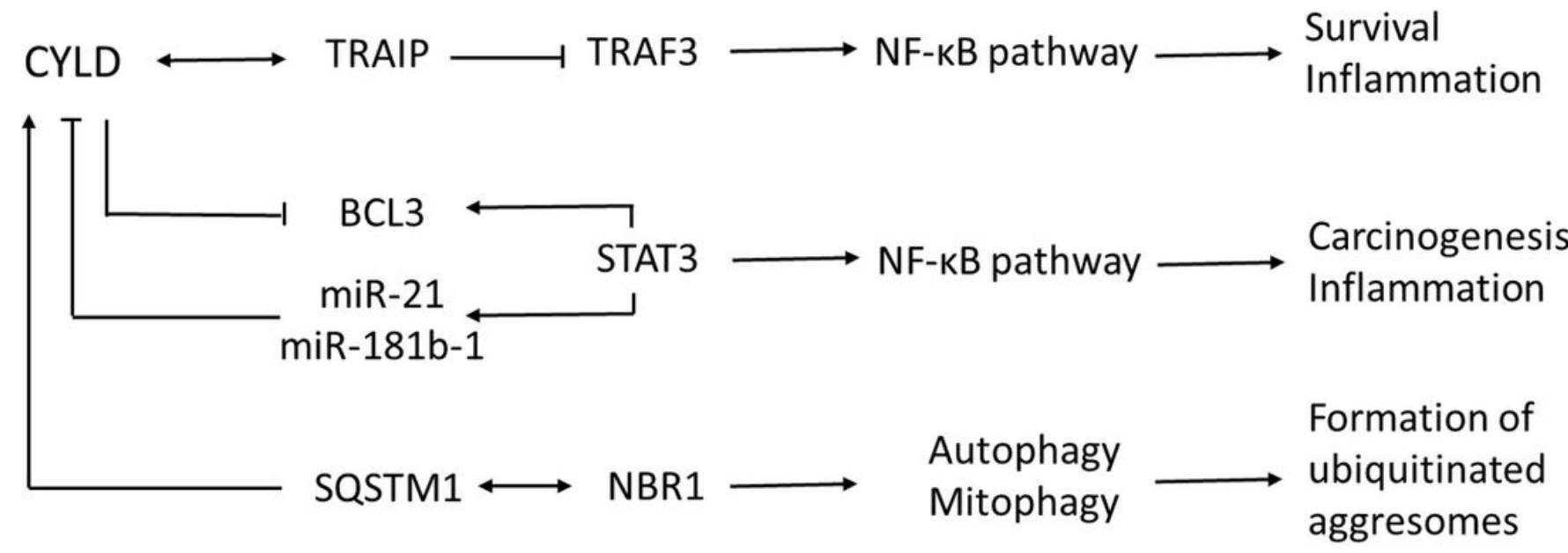

Figure 1

Schematic of the proposed mechanisms of the identified phenotype-modifying factors. 